\title{
DESAFIOS DO DESENVOLVIMENTO BRASILEIRO
}

\author{
MARCio PochmanN*
}

RESUMO: O presente artigo trata dos aspectos principais relacionados à trajetória de reestruturação do padrão de desenvolvimento capitalista. Para isso, discute o atual movimento de constituição de novas centralidades mundiais, ao mesmo tempo em que identifica os novos desafios do atual processo de desenvolvimento brasileiro.

Palavras-chave: Desenvolvimento. Sociedade. Direitos sociais.

\section{Challenges of the Brazilian development}

ABSTRACT: This article discusses the main aspects related to the restructuring trajectory of the capitalist development pattern. To this end, it discusses the current movement for the establishment of new worldwide centers, while identifying the new challenges of the current Brazilian development process.

Key words: Development. Society. Social rights.

\section{LES DEFIS DU DEVELOPPEMENT BRÉSILIEN}

RÉSUMÉ: Cet article présente les principaux aspects rapportés à la trajectoire de réorganisation du modèle de développement capitaliste. Pour cela, on discute le mouvement actuel de création de nouveaux centres à travers le monde, tout en identifiant les nouveaux défis de l'actuel processus de développement brésilien.

Mots-clés: Développement. La société. Les droits sociaux.

Instituto de Economia e Centro de Estudos Sindicais e de Economia do Trabalho da Universidade Estadual de Campinas (Unicamp). Campinas (SP) - Brasil.

Contato com o autor: <pochmann@eco.unicamp.br> 


\section{Introdução}

$\mathrm{P}$ eríodos de significativa reestruturação do sistema capitalista têm sido coincidentes com a manifestação de crises profundas no padrão de desenvolvimento. Constata-se, em geral, que os momentos de crises terminam por revelar oportunidades históricas em que as velhas formas de valorização do capital apresentam-se esgotadas, ao passo que as novas ainda não sinalizam estar suficientemente maduras.

Como o capitalismo tem dado mostras de não se reproduzir sem a existência de um centro dinâmico, capaz de estabelecer as conexões com a economia-mundo, percebe-se que o seu desenvolvimento tem sido desigual, ainda que combinado entre os diferentes espaços geográficos de acumulação de capital. Neste sentido é que se torna importante considerar os desafios atuais do desenvolvimento diante da sua maior crise observada desde a década de 1930.

Isso porque, ao longo dos últimos 150 anos, o capitalismo passou por duas situações de graves crises sucedidas por reestruturações substanciais do seu padrão de desenvolvimento. O Brasil, em especial, terminou por aproveitar essa oportunidade de turbulência internacional para se reposicionar no interior do sistema de economia-mundo de forma considerável.

Durante a longa depressão capitalista verificada entre 1873 e 1896 houve, por exemplo, avanços significativos no país em relação ao ciclo de expansão econômica associado à produção e exportação de matérias-primas e alimentos. Com os êxitos da economia cafeeira, o Brasil deu saltos materiais importantes, capazes de afiançar as novas bases da acumulação de capital imprescindíveis ao processo de industrialização.

Mesmo assim, o conservadorismo da oligarquia rural prevalecente no interior da maioria política nacional terminou por esvaziar os esforços reformistas do final do século XIX. Não obstante o ciclo de prosperidade proporcionado pela economia primário-exportadora, a elevação do padrão de vida atingiu apenas parcela minoritária da população.

A experiência da fase inicial do republicanismo brasileiro foi a de acomodação diante do anacronismo do liberalismo vigente até 1930. Assim, a República Velha (1989-1930) postergou ainda mais a já longa transição do agrarismo para a sociedade urbana e industrial, o que terminou por colocar o patamar dos direito sociais e culturais à margem das possibilidades da integração nacional. Ao final da década de 1920, o Brasil acumulava oito a cada grupo de dez residentes na condição de analfabeto, tendo menos de $4 \%$ da população participando dos processos regulares de eleições políticas. 
Com a Grande Depressão iniciada em 1929, o país conviveu novamente com uma onda de mudanças inéditas até então identificada pelo desenvolvimento capitalista primário-exportador. Pelas mãos de uma grande e heterogênea frente política tornou-se possível transitar do primitivismo associado ao velho agrarismo para a modernidade urbana e industrial, mesmo sem alterar as bases sociais e políticas predominantes no mundo rural.

A presença da maior parte do tempo ocupado por regimes políticos autoritários (Estado Novo: 1937-1945 e ditadura militar: 1964-1985) afastou a possibilidade de combinar crescimento econômico com melhor distribuição de renda, o que tornou o Brasil um dos países mais desiguais do mundo. Entre as décadas de 1930 e 1980, a economia nacional passou a ser a oitava mais importante do mundo, tendo um a cada dois habitantes na condição de pobreza.

O avanço material proporcionado pelo desenvolvimento de suas forças produtivas urbanas, especialmente industriais, ocorreu acompanhado da implantação de políticas sociais e trabalhistas voltadas somente aos ocupados formais das cidades. Após somente cinco décadas, o espaço nacional se apresentou quase que completamente urbano, com algumas áreas industriais de expressão da diversidade e integração do novo mundo da manufatura.

Apesar disso, quase a metade de sua força de trabalho permaneceu distante do sistema implementado de proteção social e do trabalho. A ausência das chamadas reformas clássicas do capitalismo contemporâneo, como a reforma fundiária, tributária e social, contribuiu para a formação de importante anomalia brasileira em relação aos êxitos do padrão de desenvolvimento registrado nos países capitalistas avançados.

Durante o projeto nacional desenvolvimentista (1930-1980), o patamar dos direitos sociais e trabalhistas expandiu-se significativamente, ainda que não se mostrasse suficiente para sua universalização. Basta dizer que o sistema educacional manteve-se apartado do conjunto da população, uma vez que nem mesmo o nível do ensino fundamental havia sido acessível a todos. No final do século $X X$, pouco mais de $7 \%$ da população etária encontrava-se matriculada no ensino superior, em comparação ao 1\% de quarenta anos antes.

A partir da crise atual do capitalismo globalizado, iniciada em 2008, o Brasil voltou a ter condições de protagonizar um novo e importante salto em seu processo de desenvolvimento. Destaca-se, contudo, a convivência de mais de duas décadas de regressão econômica e social (1980 e 1990) em meio à vigência do regime democrático sem paralelo em toda a sua história. Não fossem a Constituição Federal de 1988, os anos de baixo dinamismo econômico vigente teriam resultado em consequências sociais ainda mais graves do que a regressão do posto de oitava economia mundial, 
em 1980, para a 13ạ , no ano 2000. Não obstante o aumento de 1,8 milhão de desempregados para quase 11 milhões e a diminuição de $50 \%$ para $39 \%$ no peso relativo dos salários na renda nacional no mesmo período de tempo, o país conseguiu universalizar o acesso ao ensino fundamental.

Nos dia de hoje, o conjunto dos desafios do desenvolvimento Brasileiro faz frente à consolidação de uma nova maioria política, voltada ao desenvolvimento da economia fundada em bases sustentáveis temporal e ambientalmente. Nesta perspectiva, não parece pairar dúvida a repeito do papel central dos direitos sociais.

Em função disso, o presente artigo objetiva tratar de dois aspectos principais da trajetória de reestruturação do padrão de desenvolvimento capitalista. Inicialmente, apresenta uma breve descrição do atual movimento constitutivo de novas centralidades mundiais e, na sequência, os novos desafios associados ao processo de desenvolvimento brasileiro evidenciado pelo papel de destaque dos direitos sociais.

\section{Novas centralidades mundiais}

Na perspectiva histórica, o desenvolvimento capitalista e sua centralidade dinâmica mundial sofreram sucessivas e importantes modificações. Até a primeira metade do século XVIII, por exemplo, a região das antigas Índia e China respondia pela maior parte da produção do mundo agrário, tendo em vista a combinação de grande dimensão populacional e territorial. Com a primeira Revolução Industrial (motor a vapor, ferrovias e tear mecânico), a partir de 1750, o centro dinâmico do mundo deslocou-se para o Ocidente, mais especificamente para a Inglaterra, que se transformou na grande oficina de manufatura do mundo por conta de sua original industrialização.

O desenvolvimento industrial permitiu um salto inegável nos ganhos de produtividade, o que favoreceu um país com pouco mais de 20 milhões de habitantes, como a Inglaterra, passar a produzir em grande escala e acima do valor da produção do antigo mundo agrário. Nas antigas áreas das Índias e China habitavam mais de meio milhão de pessoas.

A divisão internacional do trabalho resultante da produção e exportação da manufatura inglesa, em relação aos produtos primários exportados pelo resto do mundo, somente sofreu modificações importantes com o avanço da segunda Revolução Industrial (eletricidade, motor à combustão e automóvel), no último quartel do século XIX. Naquela época, a onda de industrialização retardatária em curso, sobretudo nos Estados Unidos e na Alemanha, protagonizou as principais disputas em torno da sucessão da velha liderança inglesa. A sequência de duas grandes guerras mundiais (1914 e 1939) apontou não apenas para o fortalecimento estadunidense, 
como permitiu consolidar o novo deslocamento do centro dinâmico mundial da Europa (Inglaterra) para a América (EUA).

Com a Guerra Fria (1947-1991), prevaleceu a polarização mundial entre o bloco de países liderados pelos Estados Unidos e pela antiga União Soviética. Nesse período, contudo, a economia-mundo avançou consideravelmente as bases materiais do desenvolvimento, com redução no grau de assimetria entre os países, acompanhada da destruição dos antigos impérios, como o Austro-Húngaro, Otomano, Inglês, Português, entre outros.

Nos anos de 1990, contudo, o desmoronamento soviético garantiu aos Estados Unidos o exercício unipolar da dinâmica econômica mundial, embora desde a manifestação da crise global de 2008 tenham se tornado mais claros os sinais da decadência relativa estadunidense. Como resultado, o reaparecimento da multicentralidade geográfica na economia mundial terminou por expressar sinais de um novo deslocamento no interior do centro dinâmico, especialmente em relação a América (EUA) e novamente a Ásia (China).

Dessa forma, países de grande dimensão geográfica e populacional voltaram a assumir maior responsabilidade no desenvolvimento mundial, como no caso da China, Brasil, Índia, Rússia e África do Sul, que já respondem atualmente por parcela crescente da expansão econômica do planeta. Tudo isso, é claro, sem considerar as regiões de entorno dos países chamados de "baleia", pois estes impactam também sistêmica e positivamente na integração suprarregional, que se expande com maior autonomia no âmbito das relações Sul-Sul. Não sem motivos, demandam reformulações na ordem econômica global (reestruturação do padrão monetário, exercício do comércio justo, novas alternativas tecnológicas, democratização do poder e sustentabilidade ambiental).

Uma nova divisão internacional do trabalho parece ser possível, associada ao desenvolvimento das forças produtivas assentadas na agropecuária, mineração, indústria e construção civil nas economias-baleia. Também ganham importância as políticas de avanço do trabalho imaterial conectadas com a forte expansão do setor de serviços. Essa inédita fase do desenvolvimento mundial tende a depender diretamente do vigor dos novos países, que emergiram cada vez mais distantes dos pilares anteriormente hegemônicos do pensamento único (equilíbrio de poder nos Estados Unidos, sistema financeiro internacional intermediado pelo dólar e assentado nos derivativos, Estado mínimo e mercados desregulados), atualmente desacreditados.

Nesses termos, percebe-se que a reorganização mundial a partir da crise global iniciada em 2008 termina por se apoiar em uma nova estrutura de funcionamento, exigindo coordenação e liderança mais ampliada. Os países-baleia podem contribuir muito para isso, tendo em vista que o tripé da nova expansão econômica global 
consiste na alteração da partilha do mundo, derivada do policentrismo, associada à plena revolução da base técnico-científica da produção e do padrão de consumo sustentável ambientalmente.

A conexão dessa totalidade nas transformações mundiais requer o regate da cooperação e integração supranacional em novas bases. A começar pela superação da antiga divisão do trabalho entre países, assentada na reprodução do passado (menor custo de bens e serviços associado ao reduzido conteúdo tecnológico e valor agregado dependente do uso trabalho precário e da execução em longas jornadas sub-remuneradas). Com isso, o desenvolvimento poderia ser efetivamente global, evitando combinar a riqueza de alguns com a pobreza de outros.

As decisões políticas tomadas hoje pelos países de grandes dimensões territoriais e populacionais, em suas regiões de entorno, podem asfaltar, inexoravelmente, o caminho do amanhã voltado à constituição de um novo padrão civilizatório global. Para isso, contudo, torna-se estratégica a definição de uma maioria política capaz de conduzir a agenda do desenvolvimento a partir das novas centralidades mundiais.

\section{Desafios do novo desenvolvimento brasileiro}

Para que o desenho de um novo curso de crescimento econômico global não termine por repetir equívocos dos dois padrões anteriores do desenvolvimento capitalista, a questão social exige tratamento inovador em direção à maior eficiência e eficácia das políticas de Estado, ou seja: a redefinição de ações e a horizontalização do conjunto das políticas de proteção (previdência, assistência e saúde), promoção (educação, cultura e trabalho) e infraestrutura (habitação, urbanismo e saneamento) social.

Isso porque somente o imperativo da integração orçamentária e a intersetorialização das políticas públicas, articuladas por ações matriciais no plano territorial, permitirão enfrentar, em novas bases, as mudanças socioeconômicas que surgem na transição para a sociedade pós-industrial. Nos países da região, isso significa que, nas próximas décadas, a população tende a diminuir em termos absolutos e a conviver com considerável envelhecimento etário.

No Brasil, por exemplo, estima-se que em 2040 a população poderá ser de 205 milhões de habitantes, dois milhões a menos que o esperado para 2030. Isso faz com que a dependência demográfica possa aumentar diante da relativa redução da população jovem e expansão do segmento de maior idade.

Todas essas profundas mudanças demográficas encontram-se acompanhadas por alterações não menos importantes na situação familiar. A cada ano, aumenta mais a presença de famílias monoparentais e chefiadas por mulheres ou idosos. Em 
outras palavras, assiste-se à decrescente capacidade dos novos arranjos familiares proverem, por meio de decisões individuais, condições adequadas de vida, o que exige urgente redefinição do papel das políticas de atenção social. No Brasil, parcela importante da população ainda se encontra excluída das políticas de proteção e promoção social.

O avanço da sociedade moderna coloca o conhecimento na principal posição de ativo estratégico em termos de geração de renda e riqueza. Não obstante a melhora educacional dos últimos anos, o Brasil ainda se encontra muito distante do necessário patamar de ensino-aprendizagem. Tem ainda a indecência de registrar uma quantidade inaceitável de residentes analfabetos e parte restante da população com escolaridade média abaixo de oito anos, ou seja, sem o ensino fundamental completo.

Na sociedade moderna, o ensino superior passa ser a base para o ingresso no mercado de trabalho dinâmico, bem como a educação torna-se imprescindível ao longo da vida toda. Hoje, no país, menos de $14 \%$ do segmento etário de 18 a 24 anos encontram-se matriculados no ensino superior. A partir do ingresso no mercado de trabalho, em geral, as possibilidades de continuar estudando pertencem fundamentalmente à elite branca. Para os $20 \%$ mais ricos, a escolaridade média supera os dez anos, ao passo que os $20 \%$ mais pobres mal chegam aos cinco anos. Nos segmentos vulneráveis, como não brancos, nem isso ocorre.

A persistente dispersão de objetivos e a fragmentação das políticas sociais impõem elevado custo-meio de operacionalização, que poderia ser rebaixado sem maior comprometimento da efetividade e eficácia como reforma no aparelho de Estado. Ademais, o salto seria enorme em termos de enfrentamento do tradicional clientelismo e paternalismo que terminam por obstruir a perspectiva necessária da emancipação social e econômica da população beneficiada.

Por outro lado, nota-se também que a iniquidade existente no tratamento concedido ao conjunto das políticas não se localiza somente na natureza do gasto social, mas fundamentalmente na forma do seu financiamento. A prevalência da regressividade na estrutura tributária que sustenta as políticas públicas na região onera proporcionalmente mais os pobres que os ricos. Por isso, o financiamento das políticas sociais continua a potencializar o patamar da desigualdade originada na distribuição primária da renda e riqueza.

Mesmo não tendo registrado o mesmo desempenho observado nas economias centrais, os países da região conseguiram apresentar alguma melhora nas políticas de segurança social. Apesar das especificidades de um país periférico, as medidas mais recentes melhoraram em várias modalidades de atenção social, sem, contudo, romperem definitivamente com a natureza da exclusão social. Se o objetivo da questão 
social for o enfrentamento da totalidade das vulnerabilidades da população, a ação governamental de médio e longo prazos exige não apenas e exclusivamente a ação setorial, mas, sobretudo, e cada vez mais, a matricialidade das políticas de segurança social.

É nesse sentido que a proposição da consolidação das leis sociais no país assumiria importância estratégica. A necessária institucionalização dos mais recentes êxitos das políticas sociais permitiria evitar o constrangimento da descontinuidade temporal das políticas públicas, ao mesmo tempo em que possibilitaria modernizar e ampliar a capacidade do aparelho de Estado para racionalizar procedimentos e recursos.

Por fim, destaca-se que o conjunto destas medidas permitiria obter maior efetividade, eficiência e eficácia no conjunto das políticas públicas voltadas para a segurança social, especialmente quando a transição para a sociedade pós-industrial torna-se inexorável. Não obstante os obstáculos históricos e limites impostos ao avanço do sistema de bem-estar social, os países da região possuem, atualmente, a inédita oportunidade política de consolidar o rumo de um novo desenvolvimento, capaz de combinar melhora econômica com avanço social. O futuro socialmente justo e economicamente sustentável torna-se possível a partir de uma maioria política que assuma o protagonismo de conceber, junto com o povo, o que historicamente lhe foi negado: o bem-estar coletivo.

Ao mesmo tempo, deve-se considerar que os avanços técnico-científicos do começo de século XXI criam nas sociedades modernas condições superiores para a reorganização econômica e trabalhista. De um lado, o aparecimento de novas fontes de geração de riqueza, cada vez mais deslocadas do trabalho material, impõe saltos significativos de produtividade. Isso porque o trabalho imaterial liberta-se da existência prévia de um local apropriado para o seu desenvolvimento, conforme tradicionalmente ocorre nas fazendas, indústrias, canteiros de obras, escritórios, supermercados, entre tantas outras formas de organização econômica assentadas no trabalho material.

Com a possibilidade de realização do trabalho imaterial em praticamente qualquer local ou a qualquer horário, as jornadas laborais aumentam rapidamente, pois não há, ainda, controles para além do próprio local de trabalho. Quanto mais se transita para o trabalho imaterial sem regulação (legal ou negociada), maior tende a ser o curso das novas formas de riqueza que permanecem - até agora - praticamente pouco contabilizadas e quase nada repartidas entre trabalhadores, consumidores e contribuintes tributários.

Juntas, as jornadas do trabalho material e imaterial resultam em carga horária anual próxima daquelas exercidas no século XIX (quatro mil horas). Em muitos ca- 
sos, começa a haver quase equivalência entre o tempo de trabalho desenvolvido no local e o realizado fora dele. Com o computador, a internet, o celular, entre outros instrumentos que derivam dos avanços técnico-científicos, o trabalho volta a assumir maior parcela do tempo de vida do ser humano.

De outro lado, há a concentração das ocupações no setor terciário das economias. Somente nos países da região, a maior parte das novas ocupações abertas é nesse setor. Para este tipo de trabalho, o ingresso deveria ser cada vez mais acima dos 24 anos de idade, após a conclusão do ensino superior, bem como acompanhado simultaneamente pela educação para toda vida.

Com isso, distancia-se da educação tradicional voltada para o trabalho material, cujo estudo atendia fundamentalmente crianças, adolescentes e alguns jovens. Tão logo se concluía o sistema escolar básico ou médio, iniciava-se imediatamente a vida laboral sem mais precisar abrir um livro ou voltar a frequentar a escola novamente.

Para que os próximos anos possam representar uma perspectiva superior ao que se tem hoje, orna-se necessário mudar o curso originado no passado, ou seja: o desequilíbrio secular da gangorra social. Na ponta alta dessa gangorra, encontram-se os $10 \%$ mais ricos que concentram parcela significativa de toda riqueza contabilizada no Brasil. Em contrapartida, a ponta baixa da gangorra acumula o universo de excluídos, que se mantêm historicamente prisioneiros de uma brutal tributação a onerar fundamentalmente a base da pirâmide social.

No mercado nacional de trabalho também residem mecanismos de profundas desigualdades, como no caso da divisão do tempo de trabalho entre a mão de obra. Em 2010, por exemplo, a cada dez trabalhadores brasileiros, havia quase um com jornada zero de trabalho (desempregado) e quase cinco com jornadas de trabalho superiores à jornada oficial (hora extra).

O pleno emprego da mão de obra poderia ser alcançado no Brasil a partir de uma nova divisão das jornadas de trabalho, desde que mantido o nível geral de produção. A ocupação de mais trabalhadores e a ampliação do tempo de trabalho dos subocupados poderiam ocorrer simultaneamente à diminuição da jornada oficial de trabalho e do tempo trabalhado acima da legislação oficial (hora extra). Com a redistribuição do tempo de trabalho, o reequilíbrio da gangorra social torna-se possível.

$\mathrm{Na}$ transição atual da sociedade urbano-industrial para a pós-industrial, percebe-se o acúmulo de novas e importantes perspectivas para as classes trabalhadoras. Inicialmente, a ampliação da expectativa média de vida, cada vez mais próximo dos 100 anos de idade. Simultaneamente, percebe-se a forte concentração do trabalho no setor terciário das economias (serviços em geral), podendo representar cerca de $90 \%$ do total das ocupações. 
Assim, o terciário tenderia não apenas a assumir uma posição predominante, tal como representou a alocação do trabalho no setor agropecuário até o século XIX e na indústria no século $\mathrm{XX}$, como passar a exigir, por consequência, novas formas de organização e de representação dos interesses deste mundo do trabalho em transformação. Nos países desenvolvidos, por exemplo, os setores industriais e agropecuários absorvem atualmente não mais do que $10 \%$ do total dos ocupados.

Embora heterogêneo, o setor de serviços responde fundamentalmente pela dinâmica do trabalho imaterial, não mais vinculado à produção de bens tangíveis. Associa-se à produtividade imaterial e passa a ser exercido em qualquer local e horário, não mais em um espaço específico como era o mundo do trabalho na indústria, na agropecuária ou no extrativismo mineral e vegetal.

As novas tecnologias (internet e telefonia celular), em contato com as inovações na gestão da mão de obra, intensificam profundamente o exercício da atividade laboral no próprio local de trabalho. Ademais, constata-se também a extensão do trabalho exercido cada vez mais para além do espaço de trabalho, sem contrapartida remuneratória e protetiva, posto que o sistema de regulação pública do trabalho encontra-se fundamentalmente focado na empresa, como bem define o código regulatório do emprego assalariado do Brasil.

Em virtude disso, a lógica de funcionamento da economia capitalista impõe a geração de maior excedente de mão de obra, a partir de ganhos altíssimos da produtividade imaterial. Para isso, o conhecimento, e não mais a força física, torna-se importantíssimo na ampliação das novas fontes de geração de riqueza com o uso disseminado do trabalho imaterial. Nesses termos é que a estratégia da classe trabalhadora precisa ser reinventada, não apenas na defesa da realidade passada, alcançada por segmentos bem posicionados dos trabalhadores, mas no protagonismo de um novo padrão civilizatório.

No curso da nova sociedade pós-industrial, a inserção no mercado de trabalho precisa ser gradualmente postergada, possivelmente para o ingresso na atividade laboral somente após a conclusão do ensino superior, com idade acima dos 24 anos, e saída sincronizada do mercado de trabalho para o avanço da inatividade. Tudo isso acompanhado por jornada de trabalho reduzida, o que permite observar que o trabalho heterônomo deva corresponder a não mais do que $25 \%$ do tempo da vida humana.

Na sociedade agrária, o começo do trabalho se dava a partir dos 5 a 6 anos de idade para se prolongar até praticamente a morte, com jornadas de trabalho extremamente longas (14 a 16 horas por dia) e sem períodos de descanso, como férias e inatividade remunerada (aposentadorias e pensões). Para alguém que conseguisse chegar aos 40 anos de idade, tendo iniciado o trabalho aos 6 anos, por exemplo, o 
tempo comprometido somente com as atividades laborais absorvia cerca de $70 \%$ de toda a sua vida.

Naquela época, em síntese, viver era fundamentalmente trabalhar, já que praticamente não havia separação nítida entre tempo de trabalho e de não trabalho. Na sociedade industrial, o ingresso no mercado laboral foi postergado para os 16 anos de idade, garantindo aos ocupados, a partir daí, o acesso a descanso semanal, férias, pensões e aposentadorias provenientes da regulação pública do trabalho. Com isso, alguém que ingressasse no mercado de trabalho depois dos 15 anos de idade e permanecesse ativo por mais 50 anos teria, possivelmente, mais alguns anos de inatividade remunerada (aposentadoria e pensão).

Assim, cerca de 50\% do tempo de toda a vida estariam comprometidos com o exercício do trabalho heterônomo. A parte restante do ciclo da vida, não comprometida pelo trabalho e pela sobrevivência, deveria estar associada à reconstrução da sociabilidade, estudo e formação, cada vez mais exigidos pela nova organização da produção e distribuição internacionalizada.

Isso porque, diante dos elevados e constantes ganhos de produtividade, torna-se possível a redução do tempo semanal de trabalho de algo ao redor das 40 horas para não mais que 20 horas. De certa forma, a transição entre as sociedades urbano-industrial e pós-industrial tende a não mais separar nítida e rigidamente o tempo do trabalho do não trabalho, podendo gerar maior mescla entre os dois, com maior intensidade e risco da longevidade ampliada da jornada laboral para além do tradicional local de exercício efetivo do trabalho.

Diante disso, constata-se que o melhor entendimento acerca do novo mundo do trabalho possibilita a reinvenção da pauta sindical comprometida com a construção de uma sociedade superior. Não pode haver dúvidas de que o novo desenvolvimento pressupõe papel à educação.

O sistema educacional tal como existe atualmente se apresenta relativamente recente. Até a transição da antiga sociedade agrária para a urbana e industrial, a educação era algo inexistente para as grandes massas da população. Tão somente as famílias aristocráticas possuíam condições de contratar tutores para filhos, enquanto a Igreja é que tratava de transferir o conhecimento formalizado ao longo dos anos.

No mundo agrário, o conhecimento comunitário era transmitido na velha forma "de pai para filho", em que os mais idosos possuíam importância relativa superior devida ao acúmulo das experiências vividas. De maneira geral, somente a passagem para a sociedade urbana e industrial altera o papel da educação, a partir da construção e difusão das escolas formais. Antes disso, a questão nacional, constituída pelo aparecimento dos Estados nacionais a partir do século XIX, tornou-se fundamental para a generalização da condição de povo associado aos limites da 
soberania de uma nação. Assim, a unificação da língua pátria e a identificação dos valores nacionais se mostraram fundamentais para a formação do conteúdo da educação formal.

Ademais, a emergência do trabalho na manufatura passou a exigir valores como disciplina e responsabilidade fabril, bem como operações básicas e linguagem comum, não mais transmitidas pelas famílias que viviam em comunidades na sociedade agrária. Nas cidades, as famílias não somente diminuíram de tamanho como o trabalho passou a ser realizado pelos pais e distante do local de moradia.

A crise de sociabilidade no interior das famílias pertencentes à sociedade urbana e industrial terminou sendo enfrentada pela ação das políticas públicas. Com a difusão dos sistemas educacionais pelo Estado, o segmento etário de até 14 anos foi libertado do trabalho, conforme ocorria na sociedade agrária, passando a inatividade necessária a cumprir o conteúdo do ensino como elemento fundante para o ingresso no mercado de trabalho.

Uma vez coberta a fase infantil de estudo, a passagem para o mercado de trabalho afastava dos bancos escolares, posto que adultos e idosos não estudavam na sociedade urbano-industrial. Assim, a educação do século XX se apresentou funcional aos requisitos de conformação dos Estados nacionais e de transição da inatividade ao mundo do trabalho.

Com a terceira Revolução Tecnológica, que tem a emergência das novas tecnologias de comunicação e informação, as exigências educacionais ampliam-se rapidamente. Não parecem caber mais sistemas educacionais voltados apenas às fases etárias precoces.

Ademais de tornar o ensino superior o piso da nova sociedade do conhecimento, urge a instalação do sistema de educação para toda a vida. Se o conhecimento assume cada vez mais a condição de principal ativo gerador de riqueza, qual o sentido de se estudar pouco e em condições desfavoráveis?

\section{Considerações finais}

A crise mundial a partir da primeira década do século XXI poderá ser ressaltada no futuro próximo por ter promovido as bases de uma nova fase de desenvolvimento capitalista. Isso porque a crise atual se apresenta como a primeira a se manifestar no contexto do capital globalizado, uma vez que as depressões anteriores (1873 e 1929) ocorreram num mundo ainda constituído por colônias (pré-capitalista) e pela presença de experiências nacionais de economias centralmente planejadas. 
A nova fase do desenvolvimento depende crescentemente da retomada do capitalismo reorganizado, após quase três longas décadas de hegemonia neoliberal. Os quatro pilares do pensamento único (equilíbrio de poder nos Estados Unidos, sistema financeiro internacional fundado nos derivativos, Estado mínimo e mercados desregulados) tornaram-se crescentemente desacreditados. A reorganização capitalista mundial pós-crise tende a se apoiar em uma nova estrutura de funcionamento.

O tripé da expansão do capital consiste na alteração da velha partilha do mundo em função da força do policentrismo, ademais do desenlace necessário da atual ação direta do setor privado ultramonopolizado sob o Estado supranacional e, ainda, da revolução da base técnico-científica da produção e consumo sustentável ambientalmente. Com os sinais de fracasso do equilíbrio do mundo hegemonizado pelos Estados Unidos, após a queda do muro de Berlim, tornou-se mais evidente o movimento de deslocamento relativo do centro dinâmico. Diferentemente da experiência anterior de transição da hegemonia inglesa para os Estados Unidos, gradualmente consagrada pela saída da crise de 1929, percebe-se atualmente a possibilidade real do mundo pós-crise ser constituído pelo dinamismo policentrista. Ou seja, o fortalecimento de diversos centros regionais do desenvolvimento mundial.

Nos dias de hoje, os controversos sinais de decadência dos Estados Unidos parecem ser mais relativos do que absolutos, tendo em vista a desproporção econômica, tecnológica e militar ainda existente em relação ao resto dos países do mundo. Apesar disso, observa-se que, no contexto de emergência da reestruturação no centro do capitalismo mundial, ganham maiores dimensões os espaços mundiais para a construção de uma nova polaridade no sul da América Latina, para além dos Estados Unidos, da União Europeia e da Ásia.

Essa possibilidade real de partilha do mundo em novas centralidades regionais implica - ademais da coordenação de governos em torno de Estados supranacionais - aceitação de parte dos Estados Unidos em reestruturação interna. Do contrário, cabe resgatar o fato de a fase de decadência inglesa desde a Primeira Guerra Mundial ter sido demarcada por grandes disputas econômica e, sobretudo, militar entre as duas principais potências emergentes da época: Estados Unidos e Alemanha. Ao mesmo tempo, a reação sul-americana à condição de economias exportadoras de commodities para a China termina por equivaler ao retorno de uma situação que predominou até o início do século XX, de exportadores de bens primários à Inglaterra.

Por outro lado, destaca-se que, na passagem para o século XXI, o modelo de globalização neoliberal produziu, entre outros eventos, uma inédita era do poder 
monopolista privado. Até antes da crise mundial, não eram mais do que 500 corporações transnacionais com faturamento anual equivalente a quase metade do Produto Interno Bruto mundial.

No contexto pós-crise, tende a ser um contingente ainda menor de corporações transnacionais a governar qualquer setor de atividade econômica, podendo resultar na ultramonopolização privada sem paralelo histórico. Essa realidade possível faz com que os países deixem de ter empresas para que empresas passem a ter países.

A ruína da crença neoliberal explicitada pela crise atual tornou profundamente desacreditada tanto a vitalidade dos mercados desregulados como a suficiência do sistema financeiro internacional assentado nos derivativos. Por isso, espera-se que algo de novo deva surgir das práticas de socialismo dos ricos praticadas na crise internacional, por intermédio das enormes ajudas governamentais às corporações transnacionais (bancos e empresas não financeiras).

A maior interpenetração governamental na esfera dos altos negócios ultramonopolistas do setor privado global pode dar lugar ao fortalecimento de Estados supranacionais capazes de alterar as condições gerais de produção dos mercados (regulação da competição intercapitalista e apoio ao financiamento das grandes empresas). Em resumo, percebe-se que a viabilização do capital ultramonopolista global tende a depender crescentemente do fortalecimento do Estado para além do espaço nacional.

Diante da maior instabilidade do capitalismo submetido a poucas e gigantescas corporações transnacionais - muito grandes para quebrarem a partir da própria lógica do mercado -, amplia-se o papel do Estado em relação à acumulação de capital. A coordenação entre os Estados supranacionais poderá permitir a minimização das crises diante da regulação da competição intercapitalista.

Todavia, o estreitamento da relação cada vez mais orgânica do Estado com o processo de acumulação privada do capital global deve reverter-se no aprofundamento da competição entre os Estados nacionais.

Por fim, o terceiro elemento do novo tripé do possível surgimento do capitalismo reorganizado e em melhores oportunidades ao desenvolvimento latino-americano encontra-se associado a mais rápida aceleração e internalização da revolução técnico-científica no processo de produção e consumo. Pelo conhecimento produzido até o momento acerca da insustentável degradação ambiental gerada pelas atuais práticas de produção e consumo, sabe-se que a saída da crise global não deveria passar pela mera reprodução do passado.

Nesse sentido, o padrão de produção e consumo precisa ser urgentemente reconfigurado. Para isso, não apenas a matriz energética mundial vem sendo alterada 
como as alternativas de sustentabilidade ambiental tornam-se cada vez mais viáveis do ponto de vista econômico (lucrativas). Assim, as penalizações governamentais às atividades de produção e consumo degradantes ambientalmente devem crescer e serem politicamente aceitas, permitindo que um conjunto de inovações técnico-científicas possa fazer emergir um novo modelo de produção e consumo menos encadeador da maior mudança climática.

Da mesma forma, o avanço da sociedade pós-industrial, cada vez mais apoiada no avanço do trabalho imaterial, tende a viabilizar uma profunda reorganização dos espaços urbanos, fruto de exigências do exercício do trabalho em locais apropriados (fazenda para a agricultura e pecuária, fábrica e indústria para a manufatura, entre outros). Pelo trabalho imaterial, a atividade laboral pode ser exercida em qualquer local, não mais em espaços previamente determinados e apropriados para isso, bem como em qualquer horário.

Com isso, a reorganização social em comunidades territoriais torna-se possível, o que pode evitar o comprometimento temporal cotidiano com os deslocamentos da casa para o trabalho e vice-versa, entre outras tarefas comuns. Nesses termos, o fundo público precisará ser fortalecido muito mais em cima da tributação de atividades de produção e consumo ambientalmente degradantes, como nas novas formas de riqueza vinculadas à expropriação do trabalho imaterial.

Somente a maior ampliação do fundo público poderá permitir a postergação do ingresso no mercado de trabalho a partir dos 24 anos, com o estabelecimento de mecanismos que permitam o processo de educação e aprendizagem para a vida toda e, ainda, jornada laboral de até 12 horas por semana. Tudo isso, contudo, pressupõe maioria política necessária para tornar realidade o que hoje se apresenta como mera possibilidade.

Do contrário, o excedente de força de trabalho cresce, com atividades cada vez mais precárias e empobrecedoras em meio à acumulação de nova riqueza global. Para isso, as transformações do Estado latino-americano se fazem urgentes e estratégicas. No atual período democrático, há uma grande expectativa de se estabelecer os novos rumos do projeto de desenvolvimento.

Ademais do obstáculo de consagrar uma nova maioria política que ouse mais na direção da transformação da crise mundial atual, em oportunidade de maior reposicionamento do país no mundo, cabe ainda a árdua tarefa da refundação do Estado sob novas bases. Os seus eixos estruturantes podem ser três.

O primeiro consiste na reorganização administrativa e institucional, que viabilize a reprogramação de todas as políticas públicas a partir da matricialidade e integração setorial de suas especialidades. Enquanto o Estado funciona na forma de caixinhas setoriais (educação, saúde, trabalho, entre outros) e regionais, os problemas 
atuais tornam-se cada vez mais complexos e totalizantes, incapazes de serem superados pela lógica de organização pública em partes que não se comunicam, quando concorrentes entre si. A fonte disso encontra-se centrada na recuperação do sistema de planejamento democrático e transparente de médio e longo prazos.

O segundo eixo concentra-se na necessária ampliação das políticas distributivas para as redistributivas. Ou seja, a transição da melhor repartição social do orçamento governamental para a expansão da progressividade do fundo público, com a redução da carga tributária sobre a renda do trabalho e ampliação dos impostos, taxas e contribuições sobre as rendas do capital (lucro, juros, aluguel e renda da terra). Arrecadando mais e melhor, o Estado passa a alterar a desigualdade medieval que se mantém nos países da região latino-americana.

O terceiro eixo refere-se à reinvenção do mercado, tendo em vista o poder dos grandes grupos econômicos sobre o Estado. Ademais das exigências da transparência e crescente participação social, o Estado precisa reconstituir-se fundamentalmente para o verdadeiro mar que organiza os micro e pequenos negócios no país, com políticas de organização e valorização do setor por meio da criação de bancos públicos de financiamento da produção e comercialização, fundos de produção e difusão tecnológica, de assistência técnica e de compras públicas.

Esses são alguns dos passos que o Estado precisa percorrer. A sua refundação é urgente e inadiável. A oportunidade trazida pela crise mundial é real, mas depende da capacidade interna de organizar uma nova maioria política capaz de colocar em marcha o projeto de desenvolvimento sonhado por muitos e que agora ameaça se tornar realidade no Brasil.

\section{Referências}

AMARAL, L. Economia tech. Lisboa: Booknomics, 2008.

ANTUNES, R. Os sentidos do trabalho. 4. ed. São Paulo: Boitempo, 2001.

BINDÉ, J. Rumo às sociedades do conhecimento. Lisboa: Instituto Piaget, 2007.

BOISSONNAT, J. Horizontes do trabalho e do emprego. São Paulo: LTr, 1995.

BRAGA, R. A restauração do capital. São Paulo: Xamã, 1997.

CASTEL, R. As metamorfoses da questão social. Petrópolis: Vozes, 1998.

COLBARI, A. Ética do trabalho. São Paulo: Ufes, 1995.

DEJOURS, J. A banalização da injustiça social. 5. ed. Rio de Janeiro: FGV, 2003.

DINIZ, M. Os donos do saber. Rio de Janeiro: Revan, 2001. 
DUMAZEDIER, J. A revolução cultural do tempo livre. São Paulo: Sesc, 1994.

ELLSBERG, M. A educação dos futuros milionários. São Paulo: Leya, 2011.

GORZ, A. Metamorfoses do trabalho. São Paulo: AnnaBlume, 2003.

HARRIBEY, J. Le développement soutenable. Paris: Economica, 1998.

HOBSBAWM, E.J. Os trabalhadores. Rio de Janeiro: Zahar, 1981.

JACINTO, C. (Org.). Educar para que trabajo? Buenos Aires: La Crujía, 2004.

JACQUES, M.; CODO, W. (Org.). Saúde mental e trabalho. 2. ed. Petrópolis: Vozes, 2003.

JAMES, P. et al. Work of the future. Sidney: Allen \& Unwin, 1997.

KON, A. Economia de serviços. Rio de Janeiro: Campus, 2004.

KOVÁCS, I. As metamorfoses do emprego. Oeiras: Celta, 2002.

LAFARGUE, P. O direito à preguiça. São Paulo: Claridade, 2003.

LATOUCHE, E. O desafio do decrescimento. Lisboa: Instituto Piaget, 2006.

LAVILLE, A. (Org.). Envejecimiento y trabajo. Buenos Aires: Ceil/Conicet, 1993.

LAZZARATO, M.; NEGRI, A. Trabalho imaterial. Rio de Janeiro: DP\&A, 2001.

LOJKINE, J. A revolução informacional. 3. ed. São Paulo: Cortez, 1995.

MADDISON, A. The world economy: historical statistics. Paris: OECD, 2003.

MASI, D. A sociedade pós-industrial. São Paulo: Senac, 1999.

MAUSS, M.C. Ensaios de sociologia. São Paulo: Perspectiva, 2005.

MÉDA, D. El trabajo. Barcelona: Gedisa, 1998.

MÉSZÁROS, I. Desafio e o fardo do tempo histórico. São Paulo: Boitempo, 2007.

OFFE, C. Capitalismo desorganizado: transformação do trabalho e da política. São Paulo: Brasiliense, 1989.

PLIHON, D. O novo capitalismo. Coimbra: CC, 2003.

POCHMANN, M. Qual desenvolvimento? São Paulo: Publisher, 2009.

POCHMANN, M. Desenvolvimento e perspectivas novas para o Brasil. São Paulo: Cortez, 2010.

REICH, R. O trabalho das nações. São Paulo: Educator, 1995.

REQUENA, J. Propriedad intelectual y desarrollo tecnológico. São Paulo: Monte Ávila, 1991. 
RIFKIN, J. The end of work. New York: Putnam, 1995.

SANTOS, B.S. (Org.). Trabalhar o mundo. Rio de Janeiro: Civilização Brasileira, 2005.

SANTOS, N.; GAMA, A. Lazer. Coimbra: Imprensa UC, 2008.

SARACENO, C.; NALDINI, M. Sociologia da família. Lisboa: Estampa, 2003.

SAVAGE, J. A criação da juventude. Rio de Janeiro: Rocco, 2009.

SCHIRRMACHER, F. A revolução dos idosos. Rio de Janeiro: Campus, 2005.

SENNETT, R. A corrosão do caráter. Rio de Janeiro: Record, 1999.

THERBORN, G. Sexo e poder. São Paulo: Contexto, 2006.

THIRY-CHERQUES, H. Sobreviver ao trabalho. Rio de Janeiro: FGV, 2004.

VIARD, J. Éloge de la mobilité. Gemenos: Láube, 2006.

WERNECK, C. Lazer, trabalho e educação. Belo Horizonte: UFMG, 2000.

Recebido em 30 de junho de 2013.

Aprovado em 17 de julho de 2013. 